\title{
Evidence for the absorption of bile acids in the proximal small intestine of normo- and hyperlipidaemic subjects
}

\author{
B. ANGELIN, K. EINARSSON, AND K. HELLSTRÖM \\ From the Department of Medicine, Karolinska Institutet at Serafimerlasarettet, Stockholm, Sweden
}

SUMMARY Bile acid composition was determined in duodenal and jejunal aspirates obtained under fasting conditions in normolipidaemic controls and in patients with the type IIa and type IV lipoprotein patterns. In 17 out of the 22 subjects studied, the duodenal as compared with the jejunal aspirates contained proportionally more $\mathrm{CD}$ (chenodeoxycholic acid) than $\mathrm{C}$ (cholic acid). The two types of aspirates also differed slightly with regard to the $\mathrm{D}$ (deoxycholic acid): $\mathrm{CD}$ ratio, which was higher in samples drawn from the jejunum. These findings, compatible with an absorption of about $30 \%$ of $\mathrm{CD}$ in the upper small intestine, were approximately the same in all groups of patients. As evidenced by additional experiments in two subjects, an oral intake of cream does not significantly influence the absorption of $\mathrm{CD}$ in the upper small intestine.

Bile acid synthesis is regulated by a negative feedback control triggered by the amount of bile acids reaching the liver-that is, the size of the bile acid pool times the number of its enterohepatic circulations. Provided the three main bile acids are circulating through the enterohepatic system at the same rate, the ratios of the concentrations of cholic acid (C), chenodeoxycholic acid (CD), and deoxycholic acid (D) in the bile should equal the ratios of their pool sizes. Although this may be true in some individuals (Hepner et al., 1972; Pomare and LowBeer, 1974), it is not a general finding (Einarsson and Hellström, 1974; Einarsson et al., 1974a). The molar ratio between the concentrations of $C$ and $C D$ in duodenal bile of healthy subjects is often lower than the ratio between the $C$ and $C D$ pool sizes. The situation may be reversed in hyper- $\beta$-lipoproteinaemia (hyperlipoproteinaemia type II), while hyperpre$\beta$-lipoproteinaemia (hyperlipoproteinaemia type IV) is often associated with an exaggeration of the pattern encountered in controls (Einarsson et al., 1974a). These observations focus interest on bile acid absorption and initiated the present investigation of this phenomenon in the upper part of the small intestine in normo- and hyperlipidaemic subjects.

Received for publication 2 March 1976

\section{Methods}

SUBJECTS

The controls were healthy volunteers. The patients were those consecutively admitted during the study because of hyperlipidaemia. Excluded were subjects with evidence of intestinal, liver and kidney disease, hyper- or hypothyroidism, addiction to drugs or alcohol. The hyperlipoproteinaemias were characterized according to the WHO recommendations (Beaumont et al., 1970) as described earlier (Einarsson et al., 1974a). An oral cholecystography was performed in all non-cholecystectomized subjects. Clinical data are given in Table 1.

\section{EXPERIMENTAL PROCEDURE}

The subjects were provided with a double-lumen polyvinyl tube (outer diameter $5 \mathrm{~mm}$ ) that was allowed to pass into the small intestine until the upper hole had reached the distal duodenum $(80 \mathrm{~cm}$ from the teeth) and the lower hole was located in the middle jejunum (about $180 \mathrm{~cm}$ from the teeth). The position of the tube was controlled by radiography.

On the day of the study the subjects had fasted overnight. Repeated samples of intestinal content were drawn in the morning simultaneously from the two holes before as well as after intravenous injection of cholecystokinin. The subjects were allowed to drink moderate quantities of tap water (1-2 dl) dur- 


\begin{tabular}{|c|c|c|c|c|c|c|c|c|c|c|}
\hline \multirow{2}{*}{$\begin{array}{l}\text { Group of } \\
\text { subjects }\end{array}$} & \multirow{2}{*}{$\frac{M}{(n o .)}$} & \multirow[t]{2}{*}{$F$} & \multirow{2}{*}{$\begin{array}{l}\text { Age } \\
\text { (yr) }\end{array}$} & \multirow{2}{*}{$\begin{array}{l}\text { Weight } \\
(k g)\end{array}$} & \multirow{2}{*}{$\begin{array}{l}\text { Height } \\
(\mathrm{cm})\end{array}$} & \multicolumn{2}{|c|}{ Relative body weight $\dagger$} & \multirow{2}{*}{$\begin{array}{l}\text { Cholesterol } \\
(m g / d l)\end{array}$} & \multirow{2}{*}{$\begin{array}{l}\text { Triglyceride } \\
\text { (mmol/l) }\end{array}$} & \multirow{2}{*}{$\begin{array}{l}g b d^{*} \\
\text { (no.) }\end{array}$} \\
\hline & & & & & & $(\%)$ & $(>130 \%)$ & & & \\
\hline
\end{tabular}

Table 1 Basic data about the groups of subjects (means $\pm S E M$ )

*gbd = gallbladder disease.

†Calculated as $\frac{\text { weight }(\mathrm{kg})}{\text { height }(\mathrm{cm})-100} \times 100 \%$.

$\ddagger$ Significantly different from controls $\ddagger \mathrm{P}<0.01, \S_{\mathrm{P}}<0.005, \mathrm{q}_{\mathrm{P}}<0.001$.

ing the sampling period, which lasted for two to three hours. Two subjects underwent a second study. The experimental conditions were the same as outlined above, except that no cholecystokinin was administered. Instead the subjects were given $2 \mathrm{dl}$ of cream orally. Intestinal contents were obtained both before and after the aspirates became creamy.

\section{TECHNIQUES}

Serum cholesterol, $\beta$-cholesterol, triglyceride, and lipoprotein pattern were determined as described earlier (Einarsson et al., 1974a). Intestinal aspirates were hydrolysed in $1 \mathrm{M} \mathrm{KOH}$ for 12 hours at $110^{\circ} \mathrm{C}$. Before this was done, the samples obtained after the intake of cream were extracted twice with 10 volumes of light petroleum ether. The deconjugated bile acids were extracted with ethyl ether and analysed with gasliquid chromatography after being treated with diazomethane and trifluoroacetid anhydride (Einarsson et al., 1974a). Data are presented as means \pm SEM. Statistical calculations were performed with Student's paired $t$ test and the Wilcoxon signed rank sum test.

\section{Results}

Cholic acid (C), chenodeoxycholic acid (CD), and deoxycholic acid (D) clearly predominated in the bile acids in all aspirates. At any one intestinal level there was no difference in bile acid composition among samples obtained from the same individual before and after the administration of cholecystokinin and the values recorded for each subject were accordingly pooled. The very small amounts of lithocholic acid and other bile acids occasionally observed were ignored.

The molar contribution of $\mathrm{C}, \mathrm{CD}$, and $\mathrm{D}$ in duodenal aspirates obtained from the three controls without gallbladder disease (gbd) averaged 41.8 , $31 \cdot 7$, and $26.6 \%$ respectively. A somewhat different pattern, characterized by almost $50 \%$ less $\mathrm{C}$ and a reciprocal increase of $D$, was found in the two controls with gbd (Table 2). In all control subjects the duodenal aspirates contained proportionally more $\mathrm{CD}$ and $\mathrm{D}$ than the samples obtained from the jejunum. The mean $C / C D$ ratios recorded for the aspirates from these two parts of the intestine averaged $1.11 \pm 0.17$ and $1.87 \pm 0.44$ respectively. Individual values are given in Fig. 1. The corresponding figures for the $\mathrm{D} / \mathrm{CD}$ ratios were $1 \cdot 15 \pm 0.22$ and $1.29 \pm 0.24$ (Table 2).

The percentage composition of $\mathrm{C}, \mathrm{CD}$, and $\mathrm{D}$ in the aspirates from patients with the type IIa lipoprotein pattern (none of whom had gbd) was very similar to that in the controls without gbd. The $\mathrm{C} / \mathrm{CD}$ ratio was lower in duodenal (mean $1 \cdot 40 \pm 0 \cdot 16$ ) than in jejunal aspirates (mean 1.90 \pm 0.29 ) in six of the eight patients. The mean $D / C D$ ratios for the two types of aspirates were $0.93 \pm 0.20$ and $0.96 \pm 0.20$ respectively (Table 2 ).

The findings in the patients with hyperlipoproteinaemia type IV were essentially the same as those in the other two groups (Table 2, Fig. 1). D was quantitatively more important in patients with gbd and the contribution of $C D$ was higher in duodenal than in jejunal aspirates for seven out of nine subjects.

Calculated for the whole series of 22 patients, the $C / C D$ ratios as well as the $D / C D$ ratios of duodenal and jejunal aspirates correlated significantly, the $\mathrm{k}$ values being 1.30 and $1 \cdot 10$ respectively (Fig. 2 ). The $C / C D$ ratios averaged $1.24 \pm 0.08$ in duodenal and $1.73 \pm 0.16$ in jejunal aspirates $(P<0.001)$; the $\mathrm{D} / \mathrm{CD}$ ratios averaged $1 \cdot 12 \pm 0.15$ and $1.20 \pm 0.17$ $(P<0.05)$.

The results for the two subjects who received cream are listed in Table 3. No consistent differences that could be attributed to the administration of cream were observed.

\section{Discussion}

The pools of C, CD, and D normally cycle several times per day through the liver and intestine, whereby the excretion of bile acids in the bile (up to 20-30 g per day) considerably exceeds the total bile acid pool $(2-5 \mathrm{~g})$. Because of the effective uptake of bile acids 


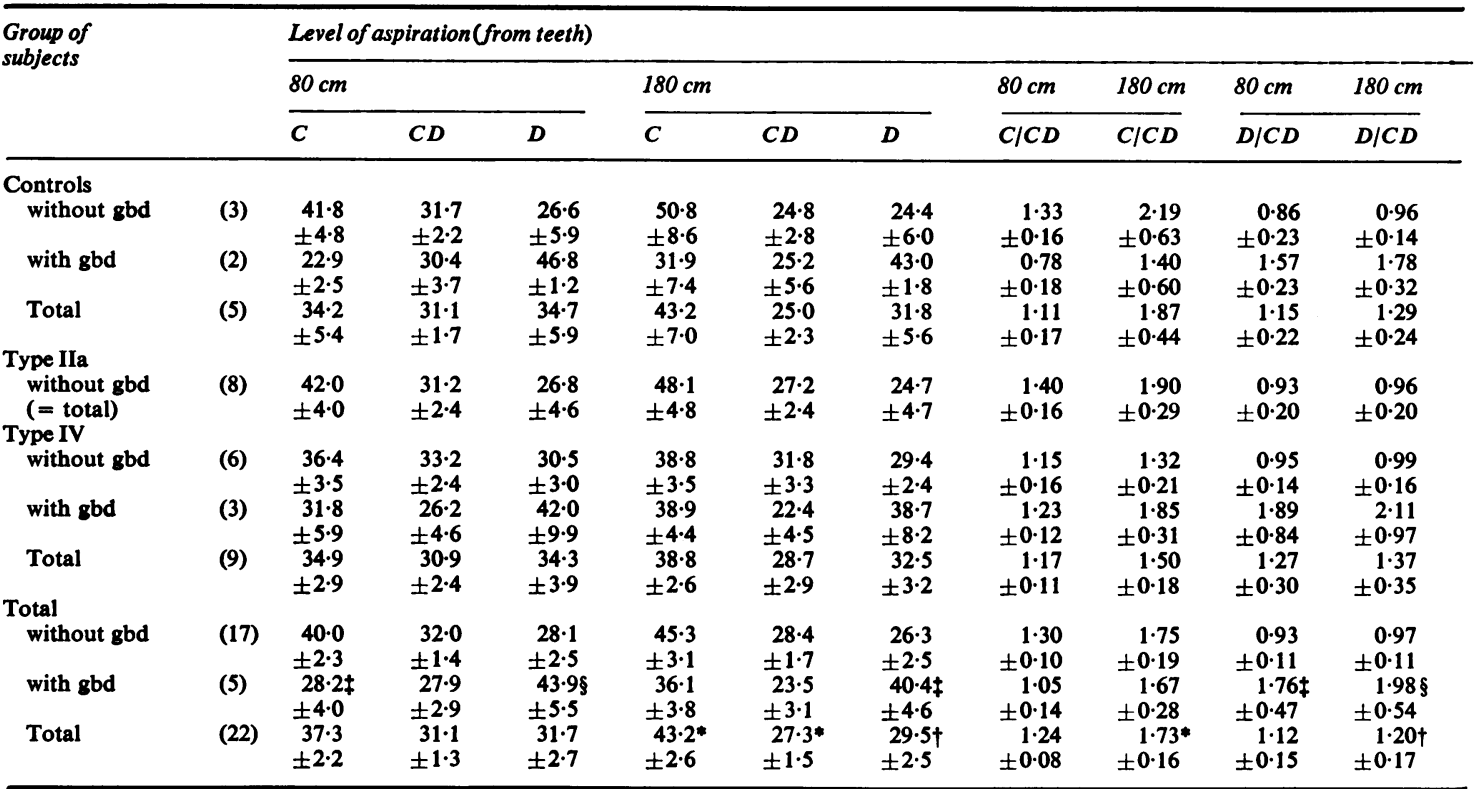

Table 2 Bile acid composition (molar per cent, means $\pm S E M$ ) in intestinal aspirates obtained from subjects without and with gallbladder disease $(g b d)$

The presence of minor amounts of other bile acids is neglected. Number of subjects within parentheses.

Significantly different (Student's paired $t$ test) from $\$ 80 \mathrm{~cm} \mathrm{P}<0.001,+80 \mathrm{~cm} \mathrm{P}<0.05, \S$ no $\mathrm{gbd} P<<0.01$. $\ddagger$ no gbd P $<0.05$,

\begin{tabular}{lcl}
\hline $\begin{array}{l}\text { Subject, } \\
\text { experimental } \\
\text { condition }\end{array}$ & $\begin{array}{l}\text { Place of aspiration } \\
\text { distance from } \\
\text { teeth }(\mathrm{cm})\end{array}$ & $\begin{array}{l}\text { Bile acid composition } \\
C: C D: D\end{array}$ \\
\hline SA & & \\
Fasting & 80 & $1.09: 1: 1 \cdot 20$ \\
Fasting & 180 & $1 \cdot 24: 1: 1.25$ \\
Cream & 80 & $1 \cdot 22: 1: 1 \cdot 39$ \\
Cream & 180 & $2 \cdot 20: 1: 1.28$ \\
LA & & $1 \cdot 26: 1: 0.51$ \\
Fasting & 80 & $1 \cdot 38: 1: 0.80$ \\
Fasting & 180 & $0.76: 1: 0.23$ \\
Cream & 80 & $1.81: 1: 0.23$ \\
Cream & 180 & \\
\hline
\end{tabular}

Table 3 Bile acid composition in intestinal aspirates obtained in two subjects when fasting and after oral intake of cream

in the intestine, the amounts of such compounds lost in the stools are relatively small.

The intestinal absorption of bile acids occurs via passive diffusion in all regions of the intestine and by an active uptake in the distal ileum (cf. Dietschy, 1968). The passive uptake of bile acids is related to the structure of the steroid derivatives, as evidenced by data on the passive permeability coefficients of ionized monomers in the rat intestine. The permeability decreases by factors of $3 \cdot 4,6 \cdot 8$, and $8 \cdot 1$ when the steroid nucleus is provided with a hydroxyl, glycine, and taurine group respectively (Schiff et al.,
1972). Studies with perfusion technique indicate that the action of the human small intestine in this respect is similar to that of the rat (Hislop et al., 1967; Switz et al., 1970; Krag and Phillips, 1974).

Duodenal bile of healthy subjects contains only conjugated bile acids with $\mathrm{C}, \mathrm{CD}$, and $\mathrm{D}$ in the ratios $1 \cdot 1: 1: 0.6$ and the ratio between glycine and taurine derivatives averages 3:1 (Sjövall, 1960). An increased amount of $\mathrm{D}$ has been found in the bile of patients with gbd (Almond et al., 1973; Pomare and Heaton, 1973; Hepner et al., 1974).

The duodenal bile acid composition in both the control and the hyperlipoproteinaemic subjects in the present study is in accordance with earlier reports (Sjövall, 1960; Einarsson et al., 1974a). In all controls, and in altogether 17 of the 22 subjects studied, the bile acids in jejunal aspirates showed a different pattern, mainly characterized by a higher contribution of $C$. In view of what is known about bile acid absorption, this change should be due to an uptake of dihydroxycholanoic acids in the proximal small intestine. As only very small amounts of conjugated $\mathrm{C}$ are absorbed in the upper small intestine (Hislop et al., 1967), the minimal uptake of $C D$ and $D$ in this area may be calculated by using $C$ as a 'non-absorbable' marker. In this way the absorption of $\mathrm{CD}$ and $\mathrm{D}$ was found to average 28 and $23 \%$, respectively, in 

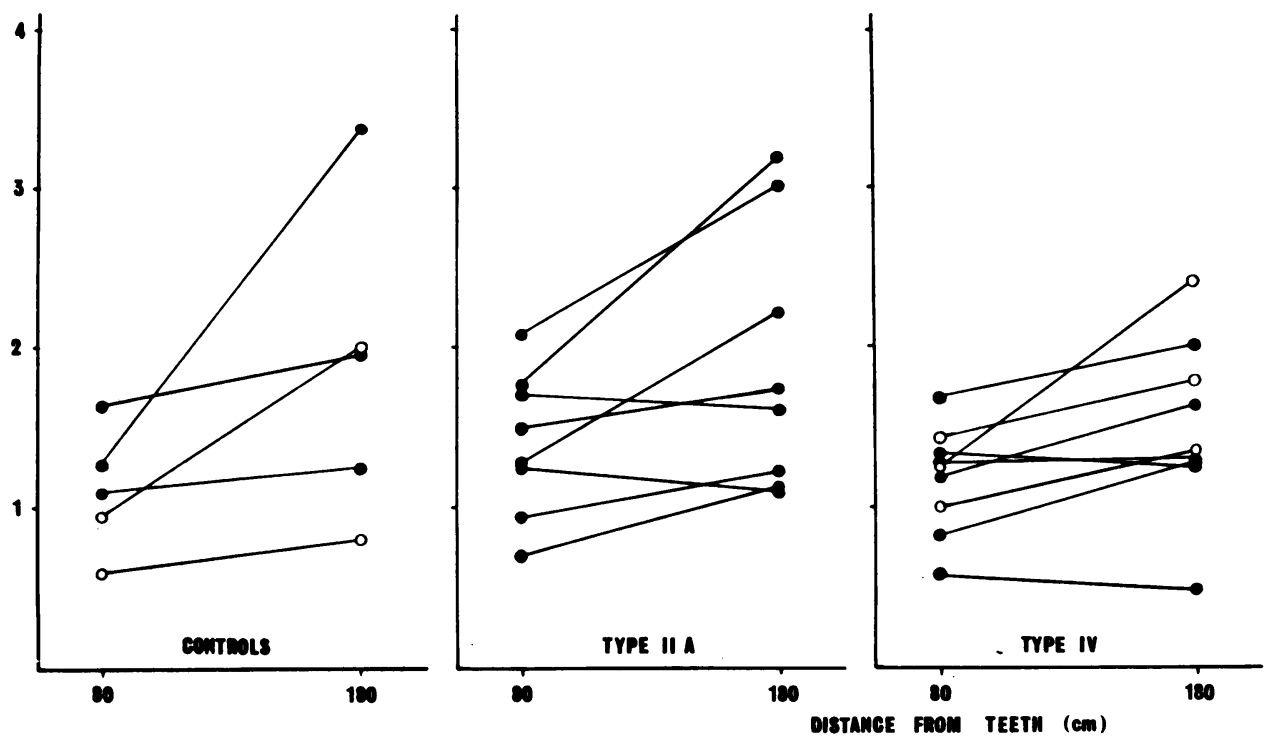

Fig. 1 Molar ratio C:CD in duodenal and jejunal aspirates obtained 80 and $180 \mathrm{~cm}$ from the teeth, respectively $O=$ subjects with gallbladder disease. In each group of subjects a significant difference between the two intestinal levels $(\mathrm{P}<0.05)$ was found using the Wilcoxon signed rank sum test.
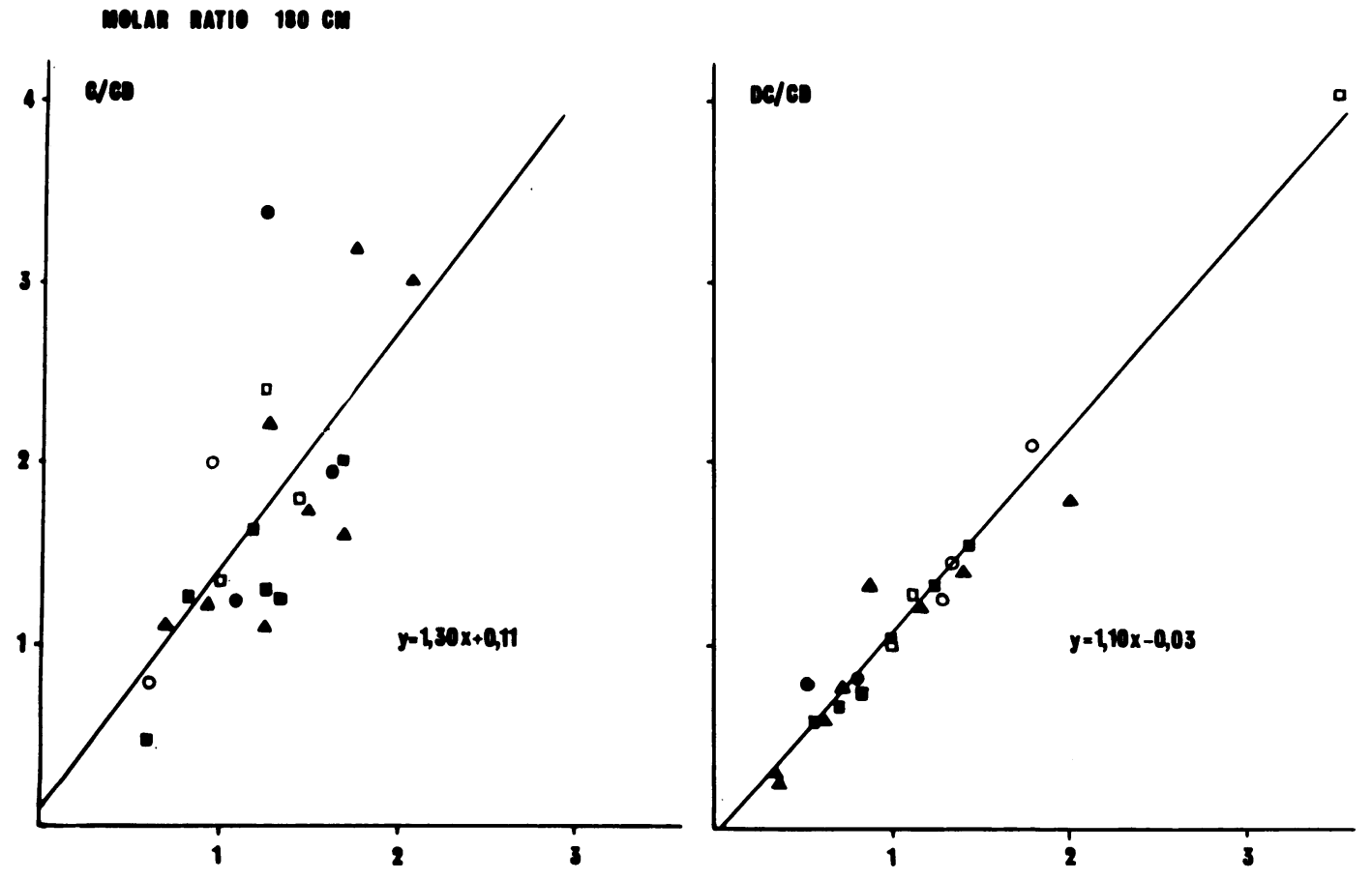

mOLAR RATIO $20 \mathrm{~cm}$

Fig. 2 Left part: relationship between C:CD molar ratio at 80 and at $180 \mathrm{~cm}$ from teeth. $R-v a l u e ~ 0.68, p<0.001$. Right part: similar relationship for D: CD. R-value 0.98, p $<0.001$. Symbols: 0 controls, $\Delta$ type IIa, $\square$ type IV; open symbols indicate subjects with gallbladder disease. 
the total material. The actual uptake of both compounds was possibly even somewhat higher, as small amounts of $\mathrm{C}$ conjugated with glycine may have been absorbed. The finding that the intake of cream did not interfere with the bile acid pattern in duodenal and jejunal aspirates suggests that the formation of mixed micelles in the small intestine does not substantially modify the passive bile acid absorption. Preliminary results from the ileal level using a similar technique (Angelin, Einarsson, and Hellström, unpublished) instead show a marked decrease in C/CD ratio along the segment studied, consistent with a different absorption pattern in this part of the intestine.

Using earlier data on pool sizes of $C$ and $C D$ in healthy controls (Einarsson et al., 1974a), it can be calculated that, for each circulation of the $\mathrm{C}$ pool, the CD pool has to circulate 1.35 times on the average to maintain the normal $C / C D$ ratio $(1 \cdot 1)$ in duodenal bile. The present data suggest that this effect is achieved by a more rapid uptake of CD in the proximal small intestine and that CD (and D) thus 'shortcuts' the hepatico-ileal bile acid circuit. The more rapid postprandial rise in blood of CD compared with C (Schalm et al., 1975; Angelin and Björkhem, to be published) lends further support to this concept.

Different rates of rotation for $C, C D$, and $D$ in the enterohepatic circulation may have some implications. It might explain why the composition of bile acids in duodenal bile does not directly reflect the ratios between the pool sizes of individual bile acids. It might also contribute to the observed increase in biliary C/CD ratio obtained after cholestyramine treatment (Dam et al., 1971; Garbutt and Kenney, 1972; Wood et al., 1972).

The $C / C D$ ratios increased similarly in normo- and hyperlipidaemic subjects during the passage of bile from duodenum to jejunum. As type IIa lipoprotein pattern is associated with a subnormal $\mathbf{C}$ pool size but a normal biliary C/CD ratio (Einarsson et al., 1974a), this would suggest that in these patients a subnormal fraction of the $C$ pool is located in the distal parts of the intestine. Many of the subjects with type IV hyperlipoproteinaemia, on the other hand, have $\mathbf{C}$ pool sizes exceeding the upper normal limits (Einarsson et al., 1974a), and it is conceivable that these patients have abnormally large amounts of this bile acid in the distal small intestine and/or in the colon. Such a phenomenon might have an explanation in common with the subnormal capacity of these patients to retain orally administered C (Einarssön et al., 1974b).

This work is part of investigations supported by the Swedish Medical Research Council (Project 19X-
3397). The skilful technical assistance of Mrs Maria Dery, Mrs Kerstin Hedström, and Miss Margret Wahlström is gratefully acknowledged.

\section{References}

Almond, H. R., Vlahcevic, Z. R., Bell, C. C., Gregory, D. H., and Swell, L. (1973). Bile acid pools, kinetics and biliary lipid composition before and after cholecystectomy. New England Journal of Medicine., 289, 1213-1216.

Beaumont, J. L., Carlson, L. A., Cooper, G. R., Fejfar, Z., Fredrickson, D. S., and Strasser, T. (1970). Classification of hyperlipidaemias and hyperlipoproteinaemias. Bulletin of the World Health Organisation, 43, 891-915.

Dam, H., Prange, I., Krogh Jensen, M., Kallehauge, H. E., and Fenger, H. J. (1971). Studies on human bile. V. Influence of cholestyramine treatment on the composition of bile in healthy subjects. Zeitschrift fur Ernährungswissen. schaft, 10, 188-197.

Dietschy, J. M. (1968). Mechanisms for the intestinal absorption of bile acids. Journal of Lipid Research, 9, 297309.

Einarsson, K., and Hellström, K. (1974). The formation of deoxycholic acid and chenodeoxycholic acid in man. Clinical Science and Molecular Medicine, 46, 183-190.

Einarsson, K., Hellström, K., and Kallner, M. (1974a). Bile acid kinetics in relation to sex, serum lipids, body weights, and gallbladder disease in patients with various types of hyperlipoproteinemia. Journal of Clinical Investigation, 54, 1301-1311.

Einarsson, K., Hellström, K., and Kallner, M. (1974b). Effect of cholic acid feeding on bile acid kinetics and neutral fecal steroid excretion in hyperlipoproteinemia (types II and IV). Metabolism, 23, 863-873.

Garbutt, J. T., and Kenney, T. J. (1972). Effect of cholestyramine on bile acid metabolism in normal man. Journal of Clinical Investigation, 51, 2781-2789.

Hepner, G. W., Hofmann, A. F., Malagelada, J. R., Szczepanik, P. A., and Klein, P. D. (1974). Increased bacterial degradation of bile acids in cholecystectomized patients. Gastroenterology, 66, 556-564.

Hepner, G. W., Hofmann, A. F., and Thomas, P. J. (1972). Metabolism of steroid and amino acid moieties of conjugated bile acids in man. II. Glycine-conjugated dihydroxy bile acids Journal of Clinical Investigation, 51, 1898-1905.

Hislop, I. G., Hofmann, A. F., and Schoenfield, L. J. (1967). Determinants of the rate and site of bile acid absorption in man. (Abstract.) Journal of Clinical Investigation, 46, 10701071.

Krag, E., and Phillips, S. F. (1974). Active and passive bile acid absorption in man. Perfusion studies of the ileum and jejunum. Journal of Clinical Investigation, 53, 1686-1694.

Pomare, E. W., and Heaton, K. W. (1973). The effect of cholecystectomy on bile salt metabolism. Gut, 14, 753-762.

Pomare, E. W., and Low-Beer, T. S. (1974). Measurement and validation of human bile salt pool size and synthesis. Clinica Chimica Acta, 57, 239-248.

Schalm, S. W., Turcotte, J., Hofmann, A. F., and Cowen, A. E. (1975). A new bile acid radioimmunoassay: development, validation, and preliminary application of an assay for chenodeoxycholyl conjugates. (Abstract.) Gastroenterology, 68, 913.

Schiff, E. R., Small, N. C., and Dietschy, J. M. (1972). Characterization of the kinetics of the passive and active transport mechanisms for bile acid absorption in the small intestine and colon of the rat. Journal of Clinical Investigation, 51, 1351-1362.

Sjövall, J. (1960). Bile acids in man under normal and patho- 
logical conditions. Clinica Chimica Acta, 5, 33-41.

Switz, D. M., Hislop, I. G., and Hofmann, A. F. (1970).

Factors influencing the absorption of bile acids by the human jejunum. (Abstract.) Gastroenterology, 58, 999.
Wood, P. D., Schioda, R., Estrich, D. L., and Splitter, S. D. (1972). Effect of cholestyramine on composition of duodenal bile in obese human subjects. Metabolism, 21, 107-116. 